\title{
Effect of Procurement Practices on Performances of Public Organizations (The Case of Essera Woreda in Dawro Zone South West Ethiopia)
}

\author{
Shimelis Begashaw Zemedagegnehu \\ Lecturer at Bonga University, College of Business and Economics, Department of Management
}

\begin{abstract}
The main objective of the study was to explain the effect of public procurement practices on performances of the organization. Procurement practices on such as procurement planning, procurement method, procurement transparency, competency of procuring staff, and contract management are independent variables in the study and the performance of the organization was dependent variable. The study used explanatory research design. The sampling technique used both probability and non-probability. The total target population of the study was 410.Among the total population 203 were scientifically selected as sample size. The data sources used in the study was primary data source. Primary data source used for data collection was questionnaires. Data were analysed by inferential statistical method. The study achieved 96\% response rate since 195 questionnaires were filled and returned out of 203 questioners distributed. Statistical package for social science (SPSS 21 version) software used to data entry. Inferential analysis used was Pearson correlation and multiple linear regression model. The findings of the study showed that procurement planning, procurement methods, procurement transparency, staff competency and contract management had significance effect on the performances of the organizations. Finally, the researcher recommended that public organizations should efficiently manage procurement practices to achieve effectively.
\end{abstract}

Keywords: public procurement, procurement planning, contract management, procurement methods

DOI: $10.7176 /$ RJFA/11-19-05

Publication date:October $31^{\text {st }} 2020$

\subsection{Background of the study}

According to world bank manual (2011) public procurement is the process by which host government including the bank's borrowers buy the inputs for vital public sector investment procurement lay foundation for national development investment in physical infrastructure and in strengthened institutions and human capabilities.

As cited by Louise k.et al.(2007) the public sector represents about 40 to $45 \%$ many economies in the developed world in terms of spend on procuring goods and services from private sectors.

According to the Federal Democratic of Ethiopia procurement agency (2011) procurement is purchasing. hiring, or obtaining by any other contractual means of goods, works, and services. It is the process of acquisition usually by means of contractual arrangement after public competition goods, works, services and other supplies by the public entity.

According to the Ministry of Finance and Economic development of Ethiopia (2010) like the other countries more than 64 percent of the total expenditure is used for procurement of goods and services.

\section{2 statement of the problem}

As cited by Sylvia et al. (2011) a lot of procurement activities still suffer from neglect, lack of proper direction ,poor coordination, slow with a lot of bureaucracy, lack of open competition and transparency, differing level of corruption, and not having a cadre of trained and qualified procurement specialists who are competent to conduct and manage the procurement process in a professional, timely, and cost effective manner.

As cited by Anteneh (2015) failure to go with plan or working with the unsound plan, the plan is not transparent, and there was the gap to make corruption and malpractices due to piece meal purchasing without market price assessment trend.

In this regard, many studies have explained the effect of procurement practices on the performances of the organization. Based on their findings: some of the studies are (OECD,2003), (Onyango,2012), (Yirga,2011), (Thai,2009) problems related with procurement planning, procurement method selection, staff competency and procurement transparency repeatedly occurred in different countries in different organizations. Furthermore, the effect of procurement practices on the performances of the organization in Ethiopia public organization was not much studied. The researcher motivated to conduct the study on the selected topic was, firstly, the effect of procurement practices on the performances of the organization is different from country to country and different from organization to organization context. Even though limited studies conducted in Ethiopia, more of these were focused at federal and regional levels. Thirdly, at woreda level procurement practices have a lot share of public expenditure for performances of the organization but study was not conducted. Therefore, this study tried to fill 
the research gap of the effect of procurement practices on the performances of the organization in Essera woreda finance and economic development office.

\subsection{Hypotheses}

1. H1: The procurement planning practices has statistically significant effect on the performance of organization.

2. H2: There is statistically significant effect between procurement methods and on the performance of organization.

3. H3: The procurement contract management practices have statistically significant effect on the performance of organization.

4. H4: The staff competency has statistically significant effect on the performance of organization.

5. H5: Public procurement transparencies have statistically significant effect on the performance of organization.

\section{4 objectives of the study}

The general objective of this study was to examine the effect of public procurement practice on the performance of organization.

\section{5 specific objectives}

1. To explain the effect of public procurement planning practices on the performance of organization.

2. To examine the effect of procurement methods on the performance of organization.

3. To explain the effect of practices of the procurement contract management on the performance of organization.

4. To examine whether staff competency level effects on the performance of organization.

5. To explain the effect of public procurement transparency on the performance of organization.

\subsection{Review of Related Literature}

\subsection{1 public procurement}

As cited by Quayle (2006) procurement means including all activities required in order to obtain the product from the supplier and get it to the place where it is actually used. Procurement encompasses the purchasing function, store, traffic and transportation, incoming inspection and quality control and assurance.

\subsection{2 procurement planning}

procurement is along and time-consuming process, contract planning should begin as quickly as the agency need known, preferably well in advance of the fiscal year in which contract award is necessary by:

- Forming a team consisting of all those who will be responsible for significant aspects of the procurement such as contracting, fiscal, legal, technical personnel.

- Coordinating with and securing the concurrence of user department in all planning.

- Consulting necessity and logistic personnel who determine type, quality, quantity and delivery requirements.

The purpose of this planning is to ensure that the procurement agents meet the agency's needs in the most effective, economical and timely manner (Thai,2009).

As cited by Donald w.Dobler and David N.Burt (1996) one of the basic requirement of goods specifications is to satisfy the procurement consideration of clear, concise, and un ambiguous communications.

\subsection{3 procurement methods}

According to Federal Democratic Republic of Ethiopia public procurement Agency (2011) procurement method is the technique that public body uses to acquire goods, works and services. The procurement methods are applicable to the procurement of goods, works, services (consultancy and noon-consultancy). The selection method focuses on a number of factors including the type of goods or services being precured, the value of the good or services being procured, the potential interest of foreign bidders and even the cost of the procurement process.

\subsection{4 procurement contract management}

According to OECD S.(2011) a contracting authority enters into a contract with economic operators, the arrangement cannot just be left to run contract must be managed to enable both contracting authority and the economic operation to meet contractual obligation .It includes frequently complex , may involve multiple actors ,may last a leading time and may consume many resources. It is therefore, vital that they are properly managed. Effective management of contract is essential to ensure that the objective of the procurement process is achieved and that all contractual obligations and activities are completed efficiently by both parties to the contract. The procurement unit must ensure that routine monitoring of all current contract is kept so that rapid remedial measures can be taken when problems arise all preventative action taken when problems are foreseen (FEDRE PPA,2011). 
Collateral guarantee agreement is important as they are normally used to current direct contractual relationships between parties for economic benefits (KINYEKO,2012).

\subsection{5 public procurement staff competency}

As cited by Basheka (2009) procurement specialist need asset of flexible skills due to changing local government. Procurement tasks strategic, tactical as well as operational skills. These skills should potentially take a larger supply chain multidisciplinary and integrative tactics. Technical skills are required to perform technical purposes in the process of procurement.

\subsubsection{Transparency of public procurement}

Adjustment of process simplified access to information that is easy to know, and availability of information, all make doing business with government much more appealing to the supplier community and though the public's trust with size and scope of government expenditure activity it is critical that all stakeholders have self-assurance in the public procurement process. A clear and informative public procurement process encourages this confidence through the free and open exchange of information, enhanced knowledge, better quality efficiency, and decrease of the potential for corruption and waste (public procurement planning standard,2012).

\subsubsection{Empirical Review of Literature}

According to research conducted by Kiam (2014) the findings indicated that $94 \%$ of the respondents were aware of the SACCO strategic plan ,majority of the respondent at $66 \%$ believes that to a very great extent that the SACCO strategic plan is attainable on the issue the strategic plan have the relevant performance pillar $53 \%$ of the respondents agree to a very great extent. The findings displayed that majority of the respondent at $41 \%$ agreed with the statement that the strategic plan promotes implementation of public procurement. Majority of the respondents on the open-ended question showed that they are still in the process of implementation of the procurement regulation.

According to Anteneh (2015) organizations have a problem in preparing clarified and complete specifications or terms of reference, and in the procurement unit besides lack of experts in preparation specification there is also skill gap preparing detail bid documents.

In general, on the literature reviewed public procurement practices were significant effect on the performances of organization.

\subsubsection{Conceptual Frameworks}

In this study, the independent variables; public procurement planning, public procurement method, procurement contract management, public procurement transparency and procuring staff competency while the dependent variable is performance of organizations.

\section{Independent variables}

\section{dependent variable}

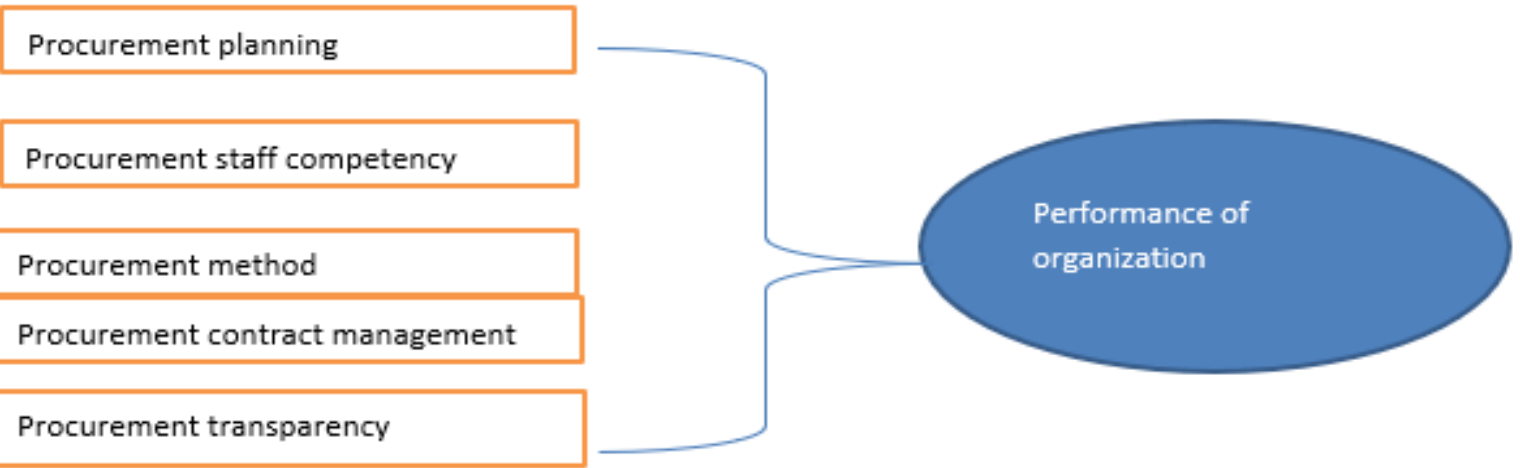

source: conceptual framework 2019

\subsection{Research design and Methodology \\ 1.7.1 Research Design}

According to Kothari (2004) research is the arrangement of conditions for collection and analysis of data in a manner that aims to combine relevance to the research purpose with economy in procedures. It is the conceptual structure with in which research is conducted; it institutes the blue print for the collection, measurement and analysis of data.

As the study intended to explain cause and effect between independent and dependent variables in the study area. Explanatory research design was used in this study. Both qualitative and quantitative approaches were employed for the study.

\subsubsection{Target population and sample size determination}

The total population of this study focused on the employees of woreda administrative offices. There are 24 
administrative offices at woreda. Out of 24 offices only 10 organizations were taken as target populations for the study by purposive probability sampling method. The total employees of 10 organizations were 410(source: Essera WFEDO, 2019). The study used simplified formula provide Yamane(1967) in order to determine the required simple size at $95 \%$ confidence level, degree of variability 0.5 and with the level of precision level of $5 \%$.

$$
\mathrm{n}=\mathrm{N} /(1+\mathrm{N})(\mathrm{e} 2)) \quad 410 /(1+410(0.0025) \quad 410 /(1+1.025) \quad=203
$$

$\mathrm{n}=$ number of sample size

$\mathrm{N}=$ total population

$\mathrm{E}=$ error of tolerance

\subsubsection{Data sources and Collection Methods}

In this research primary data sources were used. The primary data sources obtained from questioners and structured interviewed. In line with the objective of the study the research established Likert scale questioners and structured interview to collect data. Likert scale a very popular rating scale for measuring ordinal data in social science research using a 5-point Likert scale, respondents express their level of agreement or disagreement assigned $(1=$ strongly disagree, $2=$ disagree, $3=$ neither agree nor disagree, $4=$ agree, $5=$ strongly agree) .

\subsubsection{Data analysis}

The study employed inferential statistical analysis. According to Kothari (2004) by analysis mean the collection of certain indices or measures along with searching for patterns of relationship that exist among the data, groups. Analysis particularly, in the case study or experimental data, involves estimating the values of identified parameters of the population and testing of hypothesis for drawing inferences. Analyses may, therefore be characterized as inferential by using statistical package for social science (SPSS version 21). The relationship between independent and dependent variables by Pearson's correlation and multiple linear regression inferential analyses methods at 5\% significance level.

\subsubsection{Research Model}

To determine the influence of each predicator on dependent variable; multiple linear regression model is used.

Model equation; $Y=\beta 0+\beta 1 \mathrm{X} 1+\beta 2 \times 2+\beta 3 \times 3+\beta 4 \times 4+\beta 5 \times 5+\varepsilon$

The $\mathrm{Y}$ is the dependent variable performance of organizations

$\mathrm{B} 0$ is the $\mathrm{y}$-intercept; $\beta 1, \beta 2 \ldots \mathrm{B} 5$ are coefficients of predictors; $\mathrm{x} 1, \mathrm{x} 2 \ldots \mathrm{x} 5$ are independent variables $(\mathrm{x} 1$ is procurement planning; $\mathrm{x} 2$ is procurement method; $\mathrm{x} 3$ is contract management; $\mathrm{x} 4$ is staff competency; $\mathrm{x} 5$ is procurement transparency)

\subsection{Data Analysis and Discussion}

In this study ,203 questioners were distributed to respondents and 195 questioners successfully filled and returned, they were considered as the sample with a response rate of $96 \%$.

\subsubsection{Inferential Statistical Analysis}

\subsubsection{Correlation analysis}

The study used the Pearson correlation coefficient to determine the relation and strength of the correlation between the independent and dependent variables.

According to pallet (2003) a correlation coefficient enables one to quantify the strength of the linear relationship between variables. The coefficients are represented by ' $r$ ' and can be taken only the value range from -1 to +1 i.e. if $r=+1$ indicate a perfect positive correlation, and if $r=-1$ perfect negative correlation, and $r=0$ no correlation. $\mathrm{R}=0.10$ to 0.29 weak relationship, and $\mathrm{r}=0.30$ to 0.49 moderate relationship and 0.5 to 1 strong relationship. The sign may negative or positive.

Table 1 correlation between procurement practices and performances of organization

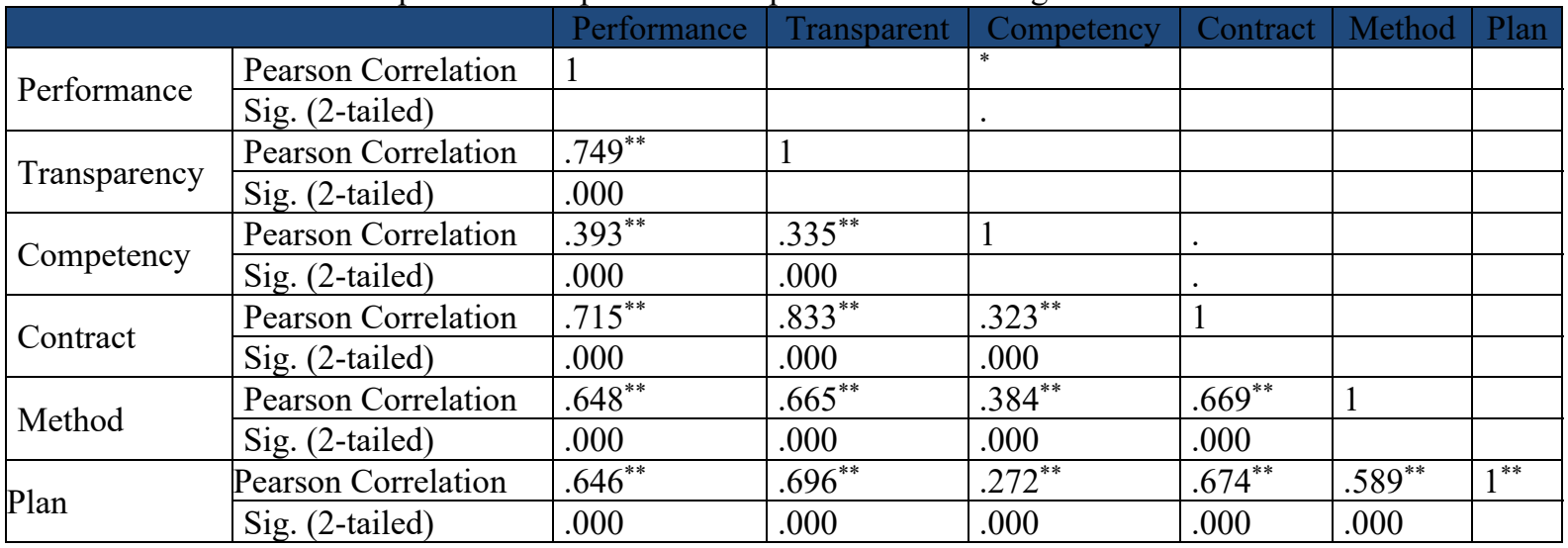

**. Correlation is significant at the 0.01 level (2-tailed) * N 195 source:2019 SPSS out put

Table 1 above indicate the relationship between procurement practices and performance of the organization. 
The result reveals that there is positive and significant relationship between procurement practices and performance of the organization (sig. level 0.01 two tailed). Moreover, procurement planning. procurement method, procurement transparency and procurement contract management had positive and strong relationship with performance of the organization $(\mathrm{r}=0.646, \mathrm{r}=0.648, \mathrm{r}=0.749, \mathrm{r}=0.715)$ respectively. The remaining procurement staff competency had moderate and positive relationship with the performance of the organization.

\subsubsection{Results of Multiple Linear Regressions Model Analysis}

From the table 4.14 below the results indicated that independent variables explained $62.8 \%$ of the variation on performance of public organizations in Essera woreda as shown by the adjusted R square. This implies that $62.8 \%$ of the corresponding change on performance of organizations can be explained by a unit change in the practices of procurement planning, procurement method, Contract management, staff competency and procurement transparency. R square values from the table 4.14 below shows that the variations in the performance of the organization account for $63.8 \%$ procurement planning, procurement method, contract management, staff competency and procurement transparency. Other factors account for $36.2 \%$ for the variation of organizations performance in the Essera woreda. The $\mathrm{R}$ value is the correlation coefficient of the independents (procurement planning, procurement method, Contract management, staff competency and procurement transparency) and the outcome or dependent variable (organizations performance) was 0.799 . The independents' overall impact on organizations performances is 0.799 .

Table 2 Model Summary

\begin{tabular}{|l|r|r|r|r|}
\hline Model & R & R Square & Adjusted R Square & Std. Error of the Estimate \\
\hline 1 & $0.799^{\mathrm{a}}$ & 0.638 & 0.628 & 0.26139 \\
\hline
\end{tabular}

a Predictors: (Constant), procurement transparency, staff competency, procurement method, procurement plan, procurement contract management

Table 3 Anova $^{\mathrm{a}}$

\begin{tabular}{|c|c|c|c|c|c|}
\hline Model & Sum of Squares & Df & Mean Square & $\mathrm{F}$ & Sig. \\
\hline Regression & 22.743 & 5 & 4.549 & 66.571 & $.000^{\mathrm{b}}$ \\
\hline Residual & 12.914 & 189 & .068 & & \\
\hline Total & 35.657 & 194 & & & \\
\hline
\end{tabular}

a. Dependent Variable: performance of organization source:2019 SPSS out put

b. Predictors: (Constant), procurement transparency, staff competency, procurement method, procurement plan, procurement contract management

The ANOVA table 3 above shows that the computed F-statistic is 66.571 with an observed significance level of less than 0.001 . Thus, the hypothesis that there is positive and significant effect between the predictors (procurement transparency, staff competency, procurement method, procurement plan, procurement contract management) and dependent variable (performance of organization) was accepted. The general objective of the study was achieved.

\section{Normality test by using histogram}

Empirical rule for asymmetrical, bell-shaped frequency distribution, approximately 68percent of the observations will lie within plus and minus one standard deviations of the mean; about $95 \%$ of the observations will lie within plus and minus two standard deviation of the mean; and practically all (99.7 percent) will lie within plus minus three standard deviations of the mean (DoglasA.et.al., 2006).

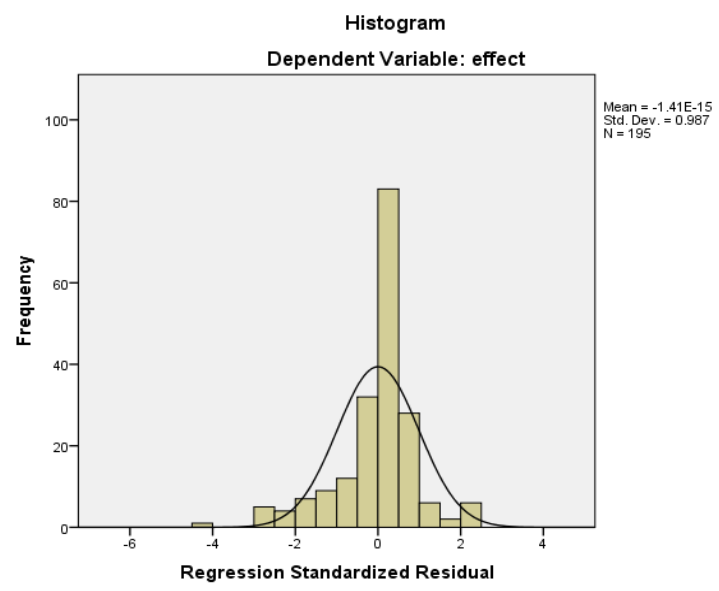

Figure 2:2019 histogram normality tests 
According to empirical rule $95 \%$ of the observations lie in plus or minus two standard deviations of 1 the mean 0 implies the distribution was normal.

\section{Multicollinearity tests}

According to Andy Field ( 2009) SPSS produces various co linearity diagnostics, one of which is the variance inflation factor (VIF) What's more, if the average VIF is greater than 1, then multicollinearity may be biasing the regression model. Related to the VIF is the tolerance statistic, which is its reciprocal (1/VIF). As such, values below 0.1 indicate serious problems. The multicollinearity checked in this study shows the tolerance value greater than 0.1 and the variance inflation factor (VIF) greater than 1 indicates multicollinearity was good.

Table 4 Coefficients ${ }^{\mathrm{a}}$

\begin{tabular}{|c|c|c|c|c|c|c|c|}
\hline \multirow[t]{2}{*}{ Model 1} & \multirow{2}{*}{$\begin{array}{l}\text { unstandardized } \\
\text { Coefficients } \\
\text { B }\end{array}$} & \multicolumn{2}{|r|}{$\begin{array}{l}\text { Standardized } \\
\text { Coefficients }\end{array}$} & \multirow[t]{2}{*}{$\mathrm{T}$} & \multirow[t]{2}{*}{ Sig. } & \multicolumn{2}{|c|}{$\begin{array}{l}\text { Collinearity } \\
\text { Statistics }\end{array}$} \\
\hline & & $\begin{array}{l}\text { Std. } \\
\text { Error }\end{array}$ & Beta & & & Tolerance & VIF \\
\hline (Constant) & -.095 & .166 & & -.572 & .568 & & \\
\hline Plan & .174 & .069 & .161 & 2.518 & .013 & .471 & 2.125 \\
\hline Method & .156 & .061 & .164 & 2.577 & .011 & .475 & 2.104 \\
\hline Contract & .163 & .080 & .170 & 2.028 & .044 & .273 & 3.667 \\
\hline Skill & .133 & .055 & .115 & 2.419 & .017 & .841 & 1.189 \\
\hline Transparency & .379 & .093 & .348 & 4.069 & .000 & .261 & 3.826 \\
\hline
\end{tabular}

$$
\text { source:2019 SPSS out put }
$$

The model equation; $\mathrm{Y}=\beta 0+\beta 1 \mathrm{X} 1+\beta 2 \times 2+\beta 3 \mathrm{x} 3+\beta 4 \mathrm{x} 4+\beta 5 \mathrm{x} 5+\varepsilon$

$\mathrm{Y}$ is the dependent variable performance of organizations

$\beta 0$ is the $y$-intercept; $\beta 1, \beta 2 \ldots \ldots+\beta 5$ are coefficients of predictors; $x 1, x 2 \ldots . . x 5$ are independent variables $(x 1$ is procurement planning; $\mathrm{x} 2$ is procurement method; $\mathrm{x} 3$ is contract management; $\mathrm{x} 4$ is staff competency; $\mathrm{x} 5$ is procurement transparency)

To predict organization performance, the study used the value presented in the unstandardized coefficient column. Using $\beta 0$ and $\beta 1, \beta 2, \beta 3, \beta 4$ and $\beta 5$ values, the prediction equation is:

$Y=-0.095+0.174 \times 1+0.156 \times 2+0.163 \times 3+0.133 \times 4+0.379 \times 5$

From the model equation above a unit change in the procurement planning was resulting in the $17.4 \%$ change in the organization's performance in the Essera woreda. This result supports the pervious study of (Onyango,2014) procurement planning influences procurement performance in the sense that they provide focused and efficient utilization of available resources, help in budgeting and planning and therefore with adequate provision of funds due to procurement plans, performance is assured. Therefore, the procurement planning had the significant effect on the organization performance were accepted. From the model equation above a unit change in procurement method practices was explaining the performance of organizations performance in the Essera woreda by 0.156 . Thus, the hypothesis of the procurement method practice had positive and significant effect on organizations performance was accepted at the significance level. 011. The organizations performance was explained by the contract management practices in 0.163 coefficients. The hypothesis of contract management practices had positive and significant effect on organizations performance was accepted. The staff competency and organization performance had the significant relation was explained by 0 . 133. The staff competency and organizations performance had significant relation was accepted at the significance level of .017 . A unit change in the procurement transparency explained 0.379 performance differences of the organizations and the procurement transparency had the positive and significant effect on the organizations performance was accepted at the significance level 0.01.This finding confirms the study findings (Mokogi N.et al., 2015) revealed that poor management of procurement processes including planning, budgeting, length of time involved, use of quotations and subcontracting directly led to inefficiencies which led to missed targets and eventual poor performance.

\subsection{1 conclusion}

The general objective of this study was to explain the effect of public procurement practice on the organization's performances. Based on the findings of the study the following conclusions were drawn.

* The correlation coefficient 0.646 revealed that procurement planning practices had the positive and positive relation on the performances of organization, and the regression result indicates that a unit change in procurement planning explained 0.174 changes in organizations performances. Therefore, procurement planning practices had significant impact on the organization performance at the significance level of 0.013 or $1.3 \%$.

* The correlation coefficient 0.648 result revealed that procurement methods positive and had significant effect on performance of the organization. The regression result showed 0.156 variations on the organization 
performance explained by a unit change in procurement method practice variation. Therefore, procurement methods practices had significant impact on the organizational performances at the significant level of 0.011 or $1.1 \%$

* The correlation coefficient 0.715 depicts that the procurement contract management practice goes positive relation with organization performance. The regression result of 0.163 showed organization performance was explained in a unit change on procurement contract management. Therefore, the procurement contract management had significant effect on the organization's performances at significant level 0.044 or $4.4 \%$.

* The correlation coefficient of 0.393 results implied organization performance had positive and significant relationship. The regression result of 0.133 explained organization performance for a unit change in the staff competency level. Therefore, the staff competency had significant impact on the organization's performances at significance level of 0.017 or $1.7 \%$.

* The correlation coefficient 0.749 revealed that procurement transparency and performance of organization had positive and significant at the $\mathrm{p}<0.01$. Regression result of 0.379 organization performance was explained by the unit variation in procurement transparency. Therefore, the procurement transparency had significant impact on organizations performances at significance level of 0.01 or $1 \%$.

\subsubsection{Recommendations}

According to conclusion on the findings, recommendations were forwarded for improvements in the procurement practice to effectively achieve organizational goals:

* The researcher recommended that procuring organization should provide continuous training for the user organizations, procurement and planning staff, which is very useful to enhance procurement more effective. Particularly, training on preparation of requirements and specification of materials, on procurement rules and regulation, and monitoring procurement plan preparation. Procuring organization should circulate after the approval of procurement plan to the user organization, the procurement plan should show the source of budget.

* In order to reduce the piecemeal purchase and direct procurement practices the organization should focus their procurement methods on open tendering methods and focus on market price need assessment.

* Moreover, organization should sign the contract agreement after the bid winner known. organizations should properly maintain contract documents in safe place to follow up the performances until the accomplishment of the activities.

* There should be continuous short-term training in order to fill skill gap of the staff. The manager should build experience sharing habit between staff members and assign right person at the right position.

\subsubsection{Future Research Direction}

The coefficient of determination shows that $63.8 \%$ of the variation in organization performances is affected by procurement planning, procurement methods, contract management, staff competency, and procurement transparency. But other researchers should study on other factors affecting the procurement practices on the performances of organizations as the regression result indicated that $36.2 \%$ the variations in organization performance for other variables.

\section{Reference}

Anteneh, G. (2015). Assessment on Procurement Planning and Implementation Effectiveness in Ethiopia: The Case of Ministry of UrbanDevelopment, Housing and Construction. unpublished .

Basheka, B. C. (2009). Public Procurement Skills Requirementframework For Local Government Systems Inuganda: Perceptions From Professionals. Journal of Public Procurement, 13.

Bhattacherjee, A. (2012). Social Science Research: Principles, Methods, and practices. Florida: Creative Commons Attribution-NonCommercial-ShareAlike.

DoglasA.et.al. (2006). basic statistics for business and economics. New York: Mc Graw Hill.

Donald W.Dobler and David N.Burt. (1996). purchasing and supply management. New

FDRE PPA, T. F. (2011). Public Procurement Manual. FDRE ,PPA .

Kiama, G. P. (2014). Factors Affecting Implementation of Public Procurement Act in SACCO

Societies in Kenya. International Journal of Academic Research in Business and Social Sciences

KINYEKI, D. S. (2012). procuremet, tendering, and contracts adminstration in developing countries:the case study of east andwest Africa. LUSAKA: ISBN.

Kothari, C. (2004). Research Methodology :methods and techniques. new delhi: New Age international publisher. Louise K.et al. (2007). Public Procurement :International cases and commentary. USA: Routledge.

MOFED, M. O. (2010). Federal public procurement directive

Mokogi N.et al. (2015). Effects of Procurement Practices on the Performance of Commercial

State-Owned Enterprises in Nairobi County. International Journal of Scientific and Research Publications, Volume 5, Issue 6, June 2015

OECD, S. (2011). support for improvement in government and mangement:contract management. Europian Union, 


\section{$2-11$.}

Onyango, C. J. (October 2014). Effects of Procurement Planning on Institutional Performance: A

Case Study of Mombasa Law Court. International Journal of Science and Research (IJSR), 2404.

ppp standard, P. P. (2012). Transparency in public procurement. Cips and nigp .

Quayle, M. (2006). Purchasing and SupplyChain Management:Strategies and Realities. London: IRM Press.

Sylvia et al. (2015). Factors affecting performance of procurementfunction among public technical training. International Journal of Economics, Commerce and Management .

WB Manual, B.-F. P. ( 2001). Procurement Policy and Services GroupOperations Policy and Country ServicesVPU. USA: World Bank.

Yamane, Taro (1973). Statistics: an introductory analysis. New York: Harper \& Row 